\title{
Designing and researching vocational mathematics education
}

\author{
Lisa Björklund Boistrup and Matilda Hällback
}

\section{Introduction}

In this chapter, we present a framework for the design of and research on collaborative teaching. We will address aspects which concern the institutional framing of teaching, as well as connections between different knowledge areas, and the modes (e.g., speech, artefacts, and body movements) in which these may be communicated. We adopt a design theoretical framework (Selander, 2008 , 2017) with the addition of a model for capturing a variety of aspects of subject knowledge (Chevallard, 2006). Our framework was developed during an action research project, with a researcher (Boistrup) and teachers (one of whom was Hällback), while drawing on both theoretical models and empirical findings. Even though the specific context of this chapter is mathematics in relation to styling (makeup and hair), the framework will offer the possibility for adoption by researchers and teachers in other areas.

We challenge the dichotomous conception where theory is viewed as something very different from practice, and where mathematics is viewed as theoretical knowledge applied to practical vocational knowledge. Rather, we view theoretical work as developed by means of a variety of resources (e.g., body movements, artefacts, speech and the like), maintained and changed over time in human practices (Selander, 2006) such as vocations and mathematics (Boistrup \& Lindberg, 2020). Rosvall et al. (2017) point to a connected tension between the workplace and so-called academic knowledge in vocational education in Sweden and Finland. This tension, as Rosvall et al. write, is exacerbated through the idea of a vocational learner as being practically oriented; using their hands instead of their heads and positioned as being in need of support. Such ideas are actually institutional norms, affecting the setting in which the teaching is designed. Through the framework presented in this chapter it is possible, in research and in teaching, to move beyond such ideas, and to strive to actively identify theoretical and practical aspects of different teaching contents (in the case of this chapter, mathematics and styling). 


\section{Other frameworks in the literature}

As described below, we argue that the framework of this chapter offers opportunities, especially vis-à-vis the design of and research on teaching in relation to how knowledge aspects are constituted by a variety of modes. In this section we make connections to perspectives in the literature of mathematics education in vocational contexts. One perspective is Bernstein's theory of pedagogic practice (2000), which has informed research on, for example, how mathematics is recontextualized into different workplace activities. One example is FitzSimons (2015), who adopted the concept of recontextualization by Bernstein when investigating vocational mathematics education taking place within an industry workplace. In this project, workers could identify unsuspected ways of mathematics being transformed in their own authentic workplace activities, while at the same time recognizing their work within its holistic context. In another study, recontextualization was adopted by Boistrup et al. (2018) in an educational setting where they identified how mathematics was relocated and transformed (i.e., recontextualized) into vocational education (viz., construction work). One conclusion, broadly speaking, is that there are at least two distinct ways to reconceptualize mathematics into vocational activities: One is the explicit use of mathematics in, for example, problem-solving, and another is that mathematical concepts and methods are integrated-and more implicitly - into the vocational activity. The framework in this chapter, which builds on Selander (2008) and Chevallard (2006), will illuminate a more nuanced version of this conclusion, with more variety in how mathematical and vocational knowledge aspects can relate to each other. The framework also addresses the roles of different modes, and the overall design of the teaching.

Another relevant theoretical perspective in the literature is Cultural Historical Activity Theory (CHAT) (e.g., Engeström, 2001). Frejd and Muhrman (2020) used CHAT to investigate the learning space available for vocational mathematics education when carried out by teams with one mathematics teacher and one vocational teacher, as was the teaching described in this chapter. Using Engeström's model, the authors investigated notions of tools, norms, division of labour, and community. They claimed that when the teaching is carried out in a vocational learning space, the setting itself facilitates students' learning of workplace mathematics. Adopting the same framework, Williams and Wake (2007) investigated mathematics as part of workplace activities. They problematized how mathematical processes have been hidden, crystallized, in what they called "black boxes," which often are instruments that carry out the mathematical algorithms needed for the work. The activity theory model contains somewhat similar notions to the learning design sequence (Selander, 2008) adopted in this chapter. The Learning Design Sequence is, however, visually and discursively outlined so that the model makes clear that notions like tools (or resources) can perform other functions in a learning setting. One 
such function is how transformations take place when knowledge is "transducted" (a term used by Kress, 2017, for changes between modes) from one mode to another. The model also distinguishes between different phases of a teaching event, which makes it relevant for the purpose of the design and analysis of teaching.

\section{The context of the chapter}

In Sweden, a large part of vocational education is included as study programs within upper secondary school, alongside study programs aiming for university studies. In these programs, the curriculum covers both knowledge specified for the vocation in question, including periods of practicum, and general knowledge areas, for example, English and Mathematics. In some schools, the vocational teacher and the mathematics teacher teach one lesson together each week, with the first year students at least. The data for this chapter stem from these lessons.

In the two lessons described and analyzed here, the styling teacher (Divo) and the mathematics teacher (Matilda) collaborated. These lessons were part of an action research project at the school where the first author of this chapter, Boistrup, was the researcher, and the second author (Hällback) was one of the teachers, and a project leaders at the school. Both authors have been engaged in the detailed analysis and the writing of this chapter. Hällback had the responsibility for transcriptions and Boistrup for how the theories were adopted when the project was carried out. The teachers took responsibility for planning and carrying out the teaching, even though the researcher (Boistrup) was able to interact during the lessons from which the data was collected. Divo Racheed (the styling teacher) was part of the initial analysis. He has read the chapter and agrees with our detailed analysis and writing. All steps in the research followed ethical guidelines, and the research was equally "owned" by the researcher and participating teachers (as described by Boistrup \& Samuelsson, 2019). Since the focus of this chapter is on the proposed framework, we will not elaborate further on these methodological aspects.

Both lessons were filmed, and photos were also taken. In the first lesson, the overall assignment was to carry out makeup (highlighting and contouring), through the adoption of triangles, drawn on a face chart (Figure 5.1a), and in the face (Figure 5.1b).

The origin of the assignment reflected by Figures $5.1 \mathrm{a}$ and $5.1 \mathrm{~b}$ was a series of lessons, taught by Divo (D) and Matilda (M), which had a focus on symmetry, both from a mathematical and a vocational point of view, where one aim of highlighting and contouring is to create an impression of a symmetrical face.

The other lesson concerned hair styling, with the overall assignment to make different types of hair curls which are created mainly by the angle between the hair and the surface of the skull (Figures 5.2a \& 2b). 


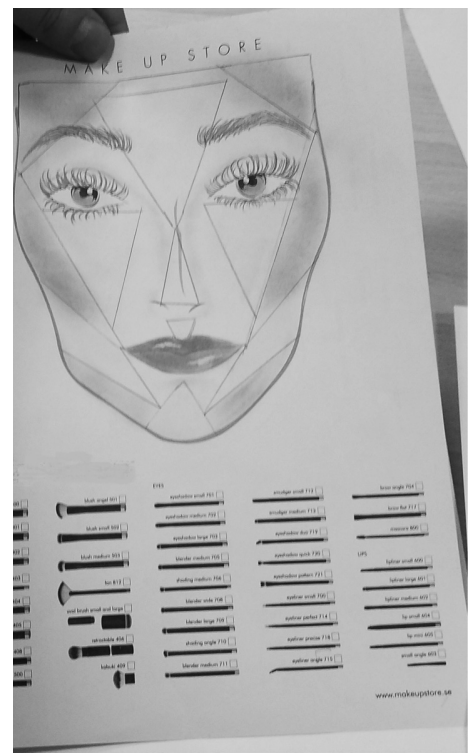

Figure 5. I a Student's face chart.

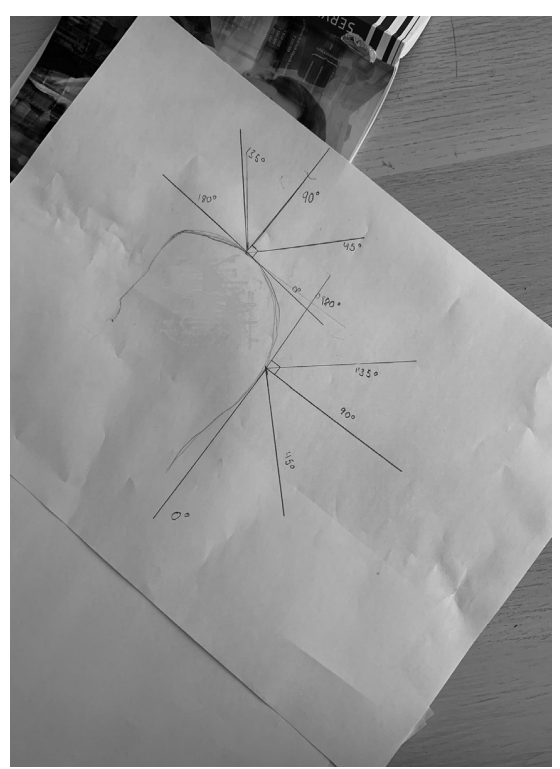

Figure 5.2a A student sheet with angles.

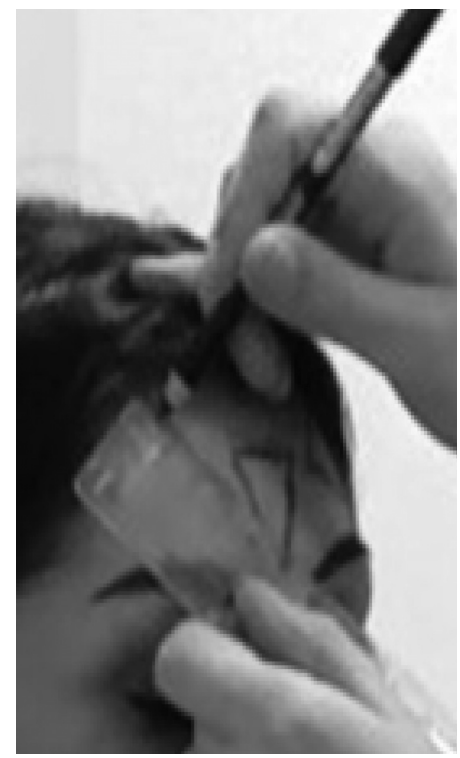

Figure 5. Ib Clip from film with a student drawing triangles.

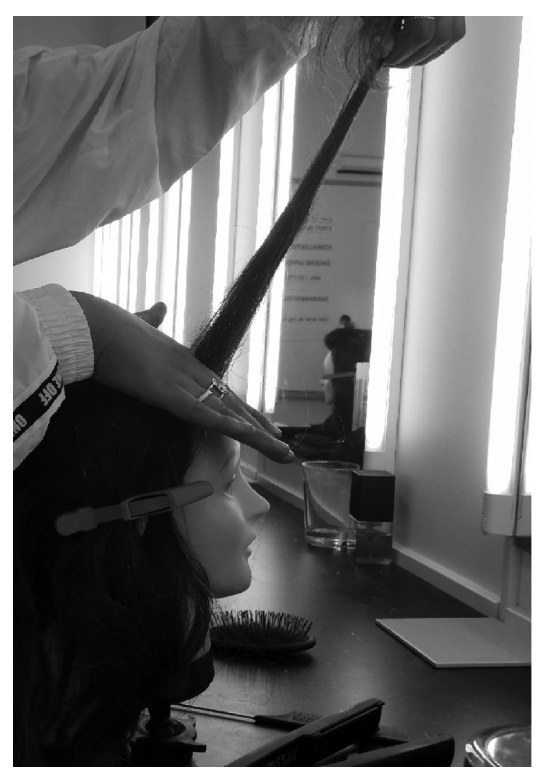

Figure 5.2b Student clarifies an angle of 90 degrees. 
In order to successfully create a certain hair style, it is essential to curl all parts of the hair at the same angle-90 degrees as in Figure 5.2, between the loop of hair and the surface of the skull.

\section{Designing teaching}

As described elsewhere in this book, Selander (2008, see also Chapter 1) presents a model for studying processes in teaching with an interest in "the formation and transformation of knowledge when people (visitors, students, etc.) engage in different processes of problem-solving, information-seeking and sign-producing activities" (p. 17) (see Figure 5.3).

On the left side in Figure 5.3, the setting is defined in terms of how a lesson, or series of lessons, starts out. The curriculum may derive from both the national level of the school system, and the local. When it comes to the national level of this chapter, the national curriculum of mathematics for vocational programs clearly states that the mathematics taught in these programs should connect to, and be affected by, respective directions of the vocation of the program. This institutional norm means that a program such as "building and construction" will have a different mathematical emphasis from a crafts-oriented program such as "styling." The curriculum at the local school level of this study expects that the mathematics teachers and vocational teachers should find connections between their respective knowledge areas, when teaching together for one lesson each week. Also, the learning resources are institutionally affected by, for example, the

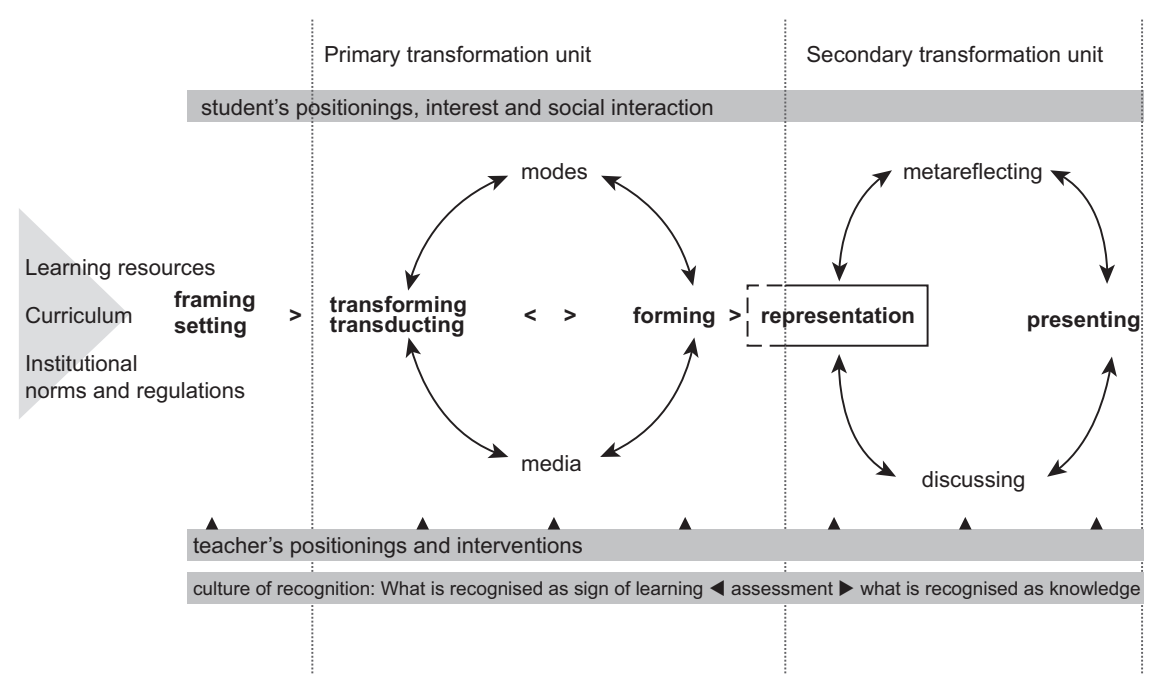

Figure 5.3 A Learning Design Sequence.

Source: (A revised version of the model in Selander, 2008, p. 17) 
organization of the teaching at a school. In this study, this concerns the location of the collaborative teaching used for vocational teaching. An institutional norm at this school is that mathematics is essential, and hence this was the chosen teaching content for the collaboration with vocational teaching.

The primary transformation unit takes place during the lesson, and here the knowledge is formed through different forms of expressions, or modes. The modes derive, implicitly or explicitly, from the interest of students and teachers in the social interaction to communicate a certain knowledge aspect at a certain moment. The expressed knowledge is also transformed within modes and transducted between different modes. One example from the hair styling lesson of this chapter is how the angles in the student sketches (see Figure 5.2a) were transducted into the activity of curling with certain angles between hair loops and the surface of the skull (as in Figure 5.2b). During the primary transformation units, teacher interventions occur when the teacher interacts with students and provides feedback (which may be viewed as part of formative assessment).

The secondary transformation unit often, but not always, takes place at the end of a lesson when the teacher and students discuss and metareflect on the teaching content of the lesson. This clearly took place in the hair styling lesson, where the styling teacher led the summarized metareflection of knowledge connected to the relation between the angle of the hair loop and the hair style. There may also be occasions where a teacher is interacting with a few students during the lesson that also have the characteristics of a secondary transformation unit, as exemplified in a following section. The knowledge in the secondary transformation unit is represented by different modes, deriving from the interest by teacher and students to make it comprehensible, and possible to present to others. Sometimes students' presentations are part of a summative assessment, in the sense that students demonstrate they have accomplished aspects of the required knowledge-for example, mathematical concepts, or overarching knowledge about styling.

The learning design sequence captures essential aspects of the design of, and research on teaching. It helps in understanding the processes of teaching and learning, not the least in the attention paid to the affordances of various modes (see Chapter 3 by Lindstrand).

\section{Theoretical and practical aspects of knowledge: praxeology}

In our action research project, we took great interest in understanding vocational knowledge aspects in relation to mathematics, and we chose to add the model of praxeology to the learning design sequence. Praxeology is a model addressing the characteristics of knowledge and is part of Chevallard's (2006) "Anthropology of the didactics" (ATD). As Castela (2015) describes it, "ATD is interested in the processes and products of what we may consider as the 
institutional cognition, that is to say, in how institutions develop their socially acknowledged capitals of practices and knowledge" (p. 8). Through ATD's interest in knowledge as constituted by institutionally framed practices, the model of praxeology is theoretically coherent with a design theory perspective.

Praxeology is constituted by praxis and logos, and offers us a foundation for addressing practical and theoretical aspects in, and the connections between, mathematics and vocational knowledge (Chevallard, 2006). Praxis (know-how) concerns tasks (types of assignments) and techniques (procedures with which the task type can be carried out). An example of a vocational task in the project was the curling of hair with three different kinds of curls, while a mathematical task was to identify the angles of 45, 90, and 180 degrees between the loop of hair and the surface of the skull. When curling the hair, aspects of vocational technique concern, for example, how to capture a loop of hair with the curling iron in a functional way. A mathematical technique could concern directing the loop of hair in the proper direction in order for the angle to be as intended. Logos (know-why) concerns technologies (why a procedure works in the way it does) and theories (overarching structures on a general level). An example of a technology connected mainly to styling was why the curling iron needs to be handled in a certain way in relation to how it affects the hair, while a mathematical technology was an explanation of why the direction of a hair loop creates a 90 degree angle and not one of 180 degrees. The main function of theory is then to provide a basis for the technology (Bosch \& Gascón, 2014). This basis may be constituted by axioms, traditions, research findings, or theoretical assumptions. An example of a theory connected to the vocational knowledge from the data was the overarching knowledge about hair styles, where curling all hair loops with the same angle creates a hair style similar to what Marilyn Monroe had, for example. Examples of theoretical aspects more connected to mathematics were what constitutes the concept of an angle, including the mathematical terminology.

Through the framework, we identified praxis and logos of both vocational and mathematical knowledge. The four Ts in the model (task, technique, technology, and theory), are intertwined and constituted by each other. Analytically, we identified them in data from the collaborative teaching in styling and mathematics.

For the analysis of knowledge aspects, we developed the analytical model in Table 5.1. The model is inspired by Boistrup et al. (2018), with an interest not

Table 5.I An analytical model for the analysis of praxis and logos, where the columns reflect a continuum between Styling and Mathematics. In the middle column there is an equal mixture of Styling and Mathematics.

\begin{tabular}{|l|l|l|l|l|l|}
\hline & \multicolumn{2}{|l|}{ Styling } & \multicolumn{3}{r|}{ Mathematics } \\
\hline Task & & & & & \\
\hline Technique & & & & & \\
\hline Technology & & & & & \\
\hline Theory & & & & & \\
\hline
\end{tabular}


only in vocational knowledge on one hand, and mathematical knowledge on the other, but also in the interfaces between the two knowledge areas.

The analytical model in Table 5.1 provides the opportunity to identify knowledge aspects that mix styling and mathematics, as well as aspects "belonging" more to either of the two knowledge areas, while at the same time identifying aspects of praxis (task and technique) and logos (technology and theory).

\section{A framework for the analysis of collaborative teaching}

In this section we coordinate the learning design sequence with the praxeology analysis model from the previous sections into a revised version of the learning design sequence. We illuminate on the one hand, the design of the teaching in terms of what modes are activated and, on the other hand, how the knowledge of mathematics and/or vocations might develop during teaching. Subsequently, we present the foundation for a framework built on the above, which may be adopted for researchers and teachers involved in questions concerning how mathematical knowledge is connected to vocational activities.

\section{A revised version of the learning design sequence}

With an interest in foregrounding knowledge aspects in relation to the learning design sequence, we added a ribbon addressing praxis and logos knowledge aspects into the model by Selander (2008) (see Figure 5.4). This is in line with the argument by Selander (2018).

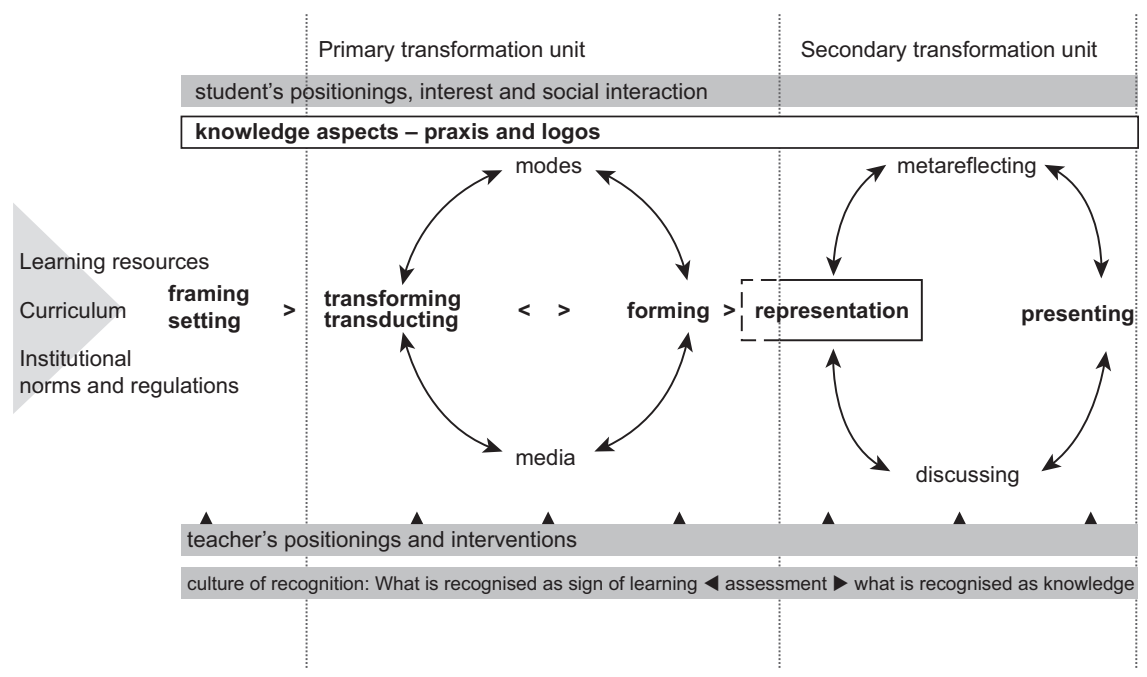

Figure 5.4 A revised version of the Learning Design Sequence, with aspects of praxeology included. 
The knowledge aspects, in terms of praxis and logos, are part of the setting (curriculum) and both transformation units. This is why the ribbon stretches sideways over the whole sequence. In the following, we provide examples of the two lessons, while illuminating the revised version of the learning design sequence. For the makeup lesson, we provide four examples, each mainly connected to one of the four Ts: task, technique, technology, and theory. All examples derive from situations where there is an interaction between a teacher or researcher and a few students. One of the examples is considered to reflect the secondary transformation unit, while the other three illuminate the primary transformation unit. For the hair styling lesson, we provide one example which takes place in the end of the lesson including all students and both teachers, and it illuminates a typical case of the secondary transformation unit.

\section{Four examples from the makeup lesson}

When it comes to the setting of the makeup lesson, the location was the styling teaching rooms, with the consequence that the learning resources connected to styling were there, with mirrors, makeup material, and so on. The mathematics teacher added learning resources to the teaching as well, which will be shown below. The curriculum in the sense of teaching content was derived from both styling and mathematics, with knowledge aspects concerning applying makeup through highlighting and contouring, and handling triangles from a mathematical perspective. The institutional norm - that there is value in drawing on vocational knowledge in the teaching of mathematics - was very much present. The overarching assignment of the lesson was a combination of these knowledge areas: to carry out facial makeup through the use of triangles. This overarching assignment consisted of task types, for example, knowing which parts of the face to highlight, and which parts to make darker through contouring. In order to make modes and resources clear, the video episode is transcribed multimodally, with columns addressing various modes (see Excerpt 5.1).

\section{The task of identifying triangles in the face during makeup (primary transformation unit)}

At the beginning of the lesson, and as part of the primary transformation unit, $M$ (the maths teacher) discusses a task type with a student: the procedure of identifying triangles in the face during makeup. $M$ starts by telling the student that she needs to make a face chart with triangles because that is what the task is about (see Figure 5.1a). She says: "The important thing now is. . that . . you:"

In Excerpt 5.1, $\mathrm{M}$ communicates with $\mathrm{S}$ through the modes of speech and body movements, and the resource of a face chart. Through this communication $\mathrm{M}$ forms the knowledge aspects in her description of the task to the student. The description mostly concerns knowledge from styling with the 


\section{Excerpt 5.I $M$ talks to a student about using a face chart. $M=$ Mathematics teacher (Matilda), $\mathbf{S}$ = Student.}

\begin{tabular}{lll}
\hline Time & Speech & Body movements and resources \\
\hline 15:33 & M: ... make one with triangles & $\begin{array}{c}\text { Points at a blank face chart } \\
\text { Holds a pencil in her hand } \\
\text { and the tip of her thumb } \\
\text { in her mouth. Looks like } \\
\text { she is pondering }\end{array}$ \\
S: Okay & M: And make it up, because \\
that's what's important now & $\begin{array}{c}\text { Sitting next to and looking } \\
\text { at the student and at the } \\
\text { table }\end{array}$ \\
15:42 & S: Can I put that makeup on? & $\begin{array}{c}\text { Points at the table and the } \\
\text { papers }\end{array}$ \\
15:55 & M: But it's really good, because & $\begin{array}{c}\text { Points at the cheek on the } \\
\text { paper where makeup is } \\
\text { shown }\end{array}$ \\
15:57 & M: ... concealer here, lighter & $\begin{array}{c}\text { Shows a triangle in an area } \\
\text { under the eye of the } \\
\text { cheek on the paper }\end{array}$ \\
\hline
\end{tabular}

additional element of mathematics because the conversation in Excerpt 5.1 clearly includes the value of triangles as part of the learning of this particular type of makeup ("do one with triangles," pointing at an empty face chart). At 15:42, S starts to transform the content to actually doing the makeup when

\begin{tabular}{|l|l|l|l|l|l|}
\hline & \multicolumn{2}{|l}{ Styling } & \multicolumn{3}{l|}{ Mathematics } \\
\hline Task & & & & & \\
\hline Technique & & & & & \\
\hline Technology & & & & & \\
\hline Theory & & & & & \\
\hline
\end{tabular}

Figure 5.5 Matilda (M) talks to a student about using a face chart. 
she points at the resources, for example, the makeup brush on the table. $\mathrm{M}$ follows up on this when she points at the cheek of the face in the chart, and emphasizes where to put the concealer, while showing a triangle in the area under the eye. The event received the following placement in the praxeology analysis model:

The position in Figure 5.5 displays that the task content (first row) of the communication above has a clear focus on styling, but also with some mathematics. Hence, the position in the second column.

The technique of placing triangles in the face (primary transformation unit)

In the following event, which is considered part of the primary transformation unit, the styling teacher (D) discusses how the students should proceed to place triangles in the face (see Figure 5.1b). Normally, a stylist does not draw triangles on a person's face with clear lines, but during this lesson students would do this to emphasize the moment of seeing triangles in the face while applying makeup. To see triangles facilitates, among other things, the work of making a face more symmetrical through makeup (which is a theoretical aspect, not highlighted by the teacher during this event). Before this event, $\mathrm{D}$ has asked some students where they can find relevant triangles on the face and had them point to such a place:

\section{Excerpt 5.2 D discusses how students should place triangles in the face. $D$ = Styling teacher (Divo), $\mathbf{S}=$ Student.}

\begin{tabular}{|c|c|c|}
\hline Time & Speech & Body movements and resources \\
\hline 20:07 & $\begin{array}{l}\text { D: You are really good; you } \\
\text { know exactly where on the } \\
\text { face the triangles should be. }\end{array}$ & $\begin{array}{l}\text { Dips his makeup brush on } \\
\text { the back of the hand, } \\
\text { stands slightly forward } \\
\text { leaning }\end{array}$ \\
\hline 20:08 & & $\begin{array}{l}\text { Carries out makeup on } \\
\text { a student under the } \\
\text { eyebrows with light } \\
\text { strokes }\end{array}$ \\
\hline $20: 16$ & $\begin{array}{l}\text { D: Here, here we should have } \\
\text { light, right? And then we take } \\
\text { all that }\end{array}$ & $\begin{array}{l}\text { D puts a lot of makeup on } \\
\text { the student's jawbone } \\
\text { and tries to show a clear } \\
\text { triangle }\end{array}$ \\
\hline
\end{tabular}


In comparison to the previously described events, the focus in Excerpt 5.2 is more on the actual technique of doing makeup with the support of triangles, than a clarification of what the task was. D articulates this in words ("you know exactly where on the face the triangles should be") in coordination with body movements and resources. The word triangle communicated through speech is transformed by $\mathrm{D}$ into body movements when he shows triangles as part of carrying out the technique of makeup. This transformation is part of making the technique clear to the students. This event is depicted in the following position in the praxeology analysis model:

\begin{tabular}{|l|l|l|l|l|l|}
\hline & \multicolumn{2}{|l|}{ Styling } & \multicolumn{4}{l|}{ Mathematics } \\
\hline Task & & & & & \\
\hline Technique & & & & & \\
\hline Technology & & & & & \\
\hline Theory & & & & & \\
\hline
\end{tabular}

Figure 5.6 Divo (D) discusses how students should place triangles in the face.

The placement in the middle column in Figure 5.6 is due to the fact that D largely directs the students' attention to the triangles of the face (part of mathematical knowledge), at the same time as he does this from a styling perspective.

\section{The technology behind seeing triangles in the face when doing makeup (secondary transformation unit)}

In the following event a student $(\mathrm{S})$ is doing the makeup on the mathematics teacher $(\mathrm{M})$. The researcher $(\mathrm{L})$ comes by and asks the student some questions. The fact that $\mathrm{L}$ is posing questions to $\mathrm{S}$, and thereby makes her metareflect and present how and why to adopt triangles when doing makeup, made us consider this to be mainly within the secondary transformation unit.

Initially, in the event of Excerpt 5.3, S indicates a number of triangles in M's face to $\mathrm{L}$ and, by the modes of speech and body movements, and resources like brush and makeup powder, she presents the makeup she applies. When doing this, she explains the techniques of contouring and highlighting through the use 


\section{Excerpt 5.3 $L$ asks $S$ about the benefits of triangles. $L=$ Researcher (Lisa), $M=$ Mathematics teacher $($ Matilda), $\mathbf{S}=$ Student.}

\begin{tabular}{|c|c|c|}
\hline Time & Speech & Body movements and resources \\
\hline $35: 00$ & $\begin{array}{l}\text { L: Well, what are you doing } \\
\text { now? }\end{array}$ & $\begin{array}{l}\text { S does makeup on M. Holds } \\
\text { a brush. Smiles }\end{array}$ \\
\hline $35: 03$ & $\begin{array}{l}\text { S: Yes, now I lay out the light } \\
\text { triangles in the face }\end{array}$ & $\begin{array}{l}\text { S does makeup on M's } \\
\text { forehead. M closes her } \\
\text { eyes. A student in the } \\
\text { background is watching. }\end{array}$ \\
\hline
\end{tabular}

[ $S$ continues to point out triangles, and then uses makeup to create a clear triangle under one of the eyes, while also describing this orally]

$35: 23$

L: But, but, when you ... to think in triangles...

$S$ focuses on $M$ with her gaze.

L: ... does it help? Does it facilitate, do you think?

S turns away to get more makeup on her brush.

[S explains that she can carry out the makeup anyhow, since she had learnt how to do it. The she adds that she imagines that they are helpful for someone who is learning]

35:35 S: And to think like this, well yes, look here, what I mean, look in the sense of triangles at the face.

$S$ takes new makeup on the brush and then continues to do makeup on M's cheek

$35: 53$ ...

S: It becomes easier to get it

S: What is bringing a part of the face out, and what ...

M blinks with her eyes and $\mathrm{S}$ puts makeup on M's other cheek

Puts makeup on M's cheek, body is turned to that side of $M$.

$35: 56$

M: Yes

$35: 59$

S: Yes, but, since, there are many people who put contour on all the way down here, and then it looks just wrong

Continues to put makeup on M's cheek.

Points at the lower part of M's cheek.

of triangles. Hence, this is considered technology. Our analysis of this is that the student sees an explanatory value when triangles are also emphasized from a mathematical perspective which justifies the placement to the right of centre (see Figure 5.7). 


\begin{tabular}{|l|l|l|l|l|l|}
\hline & \multicolumn{2}{|l|}{ Styling } & \multicolumn{3}{l|}{ Mathematics } \\
\hline Task & & & & & \\
\hline Technique & & & & & \\
\hline Technology & & & & & \\
\hline Theory & & & & & \\
\hline
\end{tabular}

Figure 5.7 Lisa (L) asks a student about the benefits of triangles.

\section{Theory aspects of triangles (primary transformation unit)}

Theory, in praxeology by Chevallard (2006), is about overall knowledge and ideas which form the basis as to why technologies can explain certain techniques. The event that we present here was interpreted to display knowledge reflecting different areas of the praxeology analysis model (see Figure 5.8).

The event analyzed in Figure 5.8 is that $M$ and a student were looking for triangles in a face chart, as a basis for the makeup to be done. The aspects of the interaction, where they looked for triangles of the face, led to the middle box in the line of technology since they were justifying how and why to use triangles when doing makeup. At the same time, they discussed the properties of the different triangles found, and this was inferred to concern theoretical aspects of mathematics:

Excerpt 5.4 shows that $M$ emphasizes that triangles can look very different. She also uses various terms that are relevant to descriptions of triangles, such as the word "base." This belongs to overall mathematical knowledge, which justifies the placement in the box in the lower right corner of Figure 5.9.

\begin{tabular}{|l|l|l|l|l|l|}
\hline & \multicolumn{2}{|l|}{ Styling } & \multicolumn{3}{|c|}{ Mathematics } \\
\hline Task & & & & & \\
\hline Technique & & & & & \\
\hline Technology & & & & & \\
\hline Theory & & & & & \\
\hline
\end{tabular}

Figure 5.8 Matilda (M) and a student are looking for triangles in the face. 


\section{Excerpt 5.4 $M$ and a student are looking for triangles in the face. $M$ = Mathematics teacher (Matilda), S = Student.}

\begin{tabular}{|c|c|c|}
\hline Time & Speech & Body movements and resources \\
\hline 23:01 & $\begin{array}{l}\text { M: Exactly } \mathrm{mm} . . . \text { and then you } \\
\text { can imagine that you have } \\
\text { a triangle kind of like this } \\
\ldots \text {. or? }\end{array}$ & $\begin{array}{l}\text { Is squatting beside S. S looks } \\
\text { at } M \text {, who makes a triangle } \\
\text { in the forehead with her } \\
\text { fingers }\end{array}$ \\
\hline \multirow[t]{2}{*}{ 23:04 } & M: Or you want it so that it ... & $\begin{array}{l}\text { Shows with her fingers in the } \\
\text { opposite direction. }\end{array}$ \\
\hline & . & \\
\hline \multirow[t]{2}{*}{$23: 24$} & $\begin{array}{l}\text { M: Hey, look at you! You can } \\
\text { really find many triangles. }\end{array}$ & Looks at the student. \\
\hline & $\ldots$ & \\
\hline $23: 32$ & $\begin{array}{l}\text { M: Here we can make rather } \\
\text { small triangles. Like this, } \\
\text { right? }\end{array}$ & $\begin{array}{l}\text { Shows with her thumb and } \\
\text { index finger how thin the } \\
\text { triangle may be. }\end{array}$ \\
\hline $23: 34$ & M: Which has a small base. & $\begin{array}{l}\text { Shows with both index } \\
\text { fingers in the air, how small } \\
\text { it may be. }\end{array}$ \\
\hline $23: 26$ & $\begin{array}{l}\text { M: But with higher sides, kind } \\
\text { of. }\end{array}$ & $\begin{array}{l}\text { Draws upwards with the } \\
\text { index fingers. } S \text { nods. }\end{array}$ \\
\hline $23: 29$ & $\begin{array}{l}\text { M: So ... there, right? Right } \\
\text { under ... }\end{array}$ & $\begin{array}{l}\text { Points at the cheek of the } \\
\text { face of the student's paper. } \\
\text { S nods. }\end{array}$ \\
\hline
\end{tabular}

\section{One example from the hair styling lesson}

For the hair styling lesson, the setting, in the sense of location, was the styling teaching rooms. The learning resources connected to styling were there, with mirrors, curling irons, and model heads to practice on (see Figure 5.2b). Also present were worksheets from a previous exercise, led by the mathematics teacher, with marked angles between the hair loop and the skull (see Figure 5.2a). The curricular knowledge was from styling, with the curling of hair, and mathematics, with the mathematical knowledge of angles. The overall assignment was to make different kinds of hair curls. This overarching assignment consisted of task types, where one was to do the three different curling loops of hair with the angles 45 , 90 , or 180 degrees, and one was to know about the three angles as mathematical objects. During the lesson these task types were present, and intertwined, in various interactions, reflecting aspects of techniques, technologies, and theory. 
Technology and theory aspects of hair curling (secondary transformation unit)

The event in this section takes place at the end of the hair styling lesson when everybody was gathered together, teachers and students, and is an example of the secondary transformation unit. $\mathrm{D}$ is summarizing, mainly through posing questions to the students, while drawing on overarching styling knowledge, how different hairstyles derive from different angles:

\section{Excerpt 5.5 Divo poses questions about what signifies different hairstyles. D = Styling teacher (Divo), S = Student.}

\begin{tabular}{ll}
\hline Time & Speech \\
\hline I8:3। & $\begin{array}{l}\text { D: So, if we want to have the } \\
\text { Hollywood hairstyle ... }\end{array}$
\end{tabular}

$18: 32$

$18: 35$

$18: 36$

$18: 38$

18:39

$18: 40$

18:54

\section{Hollywood hairstyle ...}
D: ... and a hairline that moves backwards like this.
D: What technique should we adopt then?

S: Well ...

D: If the curls are meant to go backwards like this, "wavy"

D: Which method should we use then?
D: Is it 45,90 , or 180 [degrees]?

Body movements and resources

D "forms waves" with his hands to illuminate Hollywood curls, smiles, and look at some students. $M$ stands behind, slightly on the side, with her hands in her pockets, and looks at the students.

D moves his hands along the hair, and "forms waves" with his hands. Continues to smile.

Holds hands still up in the air, where the "formingwaves" move ended

[Not visible]

Shows with his hands again,

Puts his hand on his waist.

Holds I, 2, and 3 fingers to clarify the three methods.

[One student answers 90 degrees and the next says 45 , which $D$ answers is correct. D makes connections again between the angle and the hairstyle that is created ("They go backwards, they go from the side," Shows with the hand from the forehead and

backwards, "shape waves"). Then, D asks the next question:]
D: Marilyn Monroe ...? the head to show much volume. 


\begin{tabular}{|c|c|c|}
\hline Time & Speech & Body movements and resources \\
\hline 18:55 & D: Big curls & $\begin{array}{l}\text { Shows big curls with his } \\
\text { hands. }\end{array}$ \\
\hline 18:55 & S: Right ... & $\begin{array}{l}\text { D still shows curls with his } \\
\text { hands }\end{array}$ \\
\hline $18: 56$ & $\begin{array}{l}\text { D: And volume, the } 60 \text { s, } \\
\text { Hairspray? }\end{array}$ & $\begin{array}{l}\text { Shows volume with his hands } \\
\text { above his head. }\end{array}$ \\
\hline \multirow[t]{2}{*}{ 18:58 } & $\begin{array}{l}\text { D: How many degrees would } \\
\text { that be? }\end{array}$ & Looks at the students. \\
\hline & \multicolumn{2}{|c|}{$\begin{array}{l}\text { [A student answers I } 80 \text { degrees and D confirms that this is true. } \\
\text { He ends the event by saying that the students "are in control"] }\end{array}$} \\
\hline
\end{tabular}

The overall knowledge (theor $y$ ) that D emphasizes in the event of Excerpt 5.5 is about what characterizes different hairstyles. This is knowledge that forms the basis for the explanations that D also gives (technology), which in itself affects the methods, with different angles, that were used during other events in the lesson (techniques). This is reflected in Figure 10:

There is a certain emphasis on the three angles in these events, but they are really a detail in relation to D's rich description of the different hairstyles, which is why we chose the boxes at the far left of the praxeology analysis model. The fact that aspects belonging to theory are found in parallel with aspects belonging to technology is not so surprising. Our interpretation is based on the fact that an overall knowledge aspect (theory) in a teaching situation is motivated by a teacher or student wanting to explain something, which often reflects technology.

\begin{tabular}{|l|l|l|l|l|l|}
\hline & \multicolumn{2}{|l}{ Styling } & \multicolumn{3}{l|}{ Mathematics } \\
\hline Task & & & & & \\
\hline Technique & & & & & \\
\hline Technology & & & & & \\
\hline Theory & & & & & \\
\hline
\end{tabular}

Figure 5.9 Divo (D) poses questions about what signifies different hairstyles. 


\section{Conclusions}

In this chapter, we have illuminated how it is possible to carry out detailed analysis of data from collaborative teaching, with attention to design aspects concerning, for example, transformations between modes/resources, and practical and theoretical aspects of knowledge. We have drawn on the frequently adopted learning design sequence, while also adding an elaborate focus on aspects of knowledge. With the attention to how such aspects can be understood as part of practices, we have contributed with a framework which adopts the assumptions from the original learning design sequence. The perspectives of this chapter can be viewed as a didactic model possible to adopt for teachers and researchers with a specific knowledge interest, such as collaborative teaching in, for example, mathematics and vocational subjects.

From a design theoretical perspective, this chapter illuminates the setting of the teaching in terms of the institutional norms of the school where it was promoted that mathematics should be integrated with vocational teaching for one lesson a week. Another setting aspect concerns resources, where the chapter describes how the styling classroom had many authentic artefacts which helped to strengthen knowledge aspects of styling and mathematics. This is similar to the findings of Frejd and Muhrman (2020), although the framework of this chapter extended the multimodal focus of the analysis which also deepened the understanding of the meaning-making that was afforded through the teaching. One example in the form of an artefact was the face chart, which is normally used in styling practices, but was now used with a focus on mathematical aspects such as symmetry and triangles as well. This focus, in turn, helped the styling content to be more clearly articulated. Through the transformation units of the learning design sequence, it was possible to identify how knowledge aspects were transformed between modes, and how this affected the extent to which the knowledge aspects reflected mathematics and styling, and also whether it was mainly about praxis or logos.

In this chapter, the two content areas were mathematics and styling. As described in the introduction, other studies with an interest in knowledge aspects of mathematics in vocational contexts have adopted recontextualization by Bernstein (2000) (see, e.g., Boistrup et al., 2018; FitzSimons, 2015). Similarly to these studies, this chapter aimed to take these contexts seriously and not take for granted that mathematics in vocational activities is simply materialized as school mathematics (see also FitzSimons, 2002). The framework of this chapter adds new ways of capturing the character of the mathematical and vocational knowledge in an educational setting, and how these knowledge areas can relate to each other in many different ways, through a variety of modes.

In order to develop a fruitful collaborative teaching setting between knowledge areas such as mathematics and vocational education, as in the case of this 
chapter, the teachers within the collaboration need to be willing to challenge their taken-for-granted assumptions and, hence, to go beyond the traditional discourse of the content to be taught. An open-minded view of the subjects, mathematics and styling, was consequently taken as a condition for the development of a rewarding collaborative teaching and research project. This facilitated the research, since more opportunities were created for understanding design theoretical aspects of mathematics and vocational knowledge in relation to each other. The teachers together, and sometimes with the researcher, explored what (undetected) content was "hiding" within both subjects, in a variety of modes. Also included here is the need to take both subjects' contents and resources seriously, and to look at both knowledge areas as equally relevant. Furthermore, this was a way to handle the tension, described by Rosvall et al. (2017), between workplace and so-called academic knowledge in vocational education.

For a teacher in upper secondary school, specializing in one or maybe two subjects, it is easy to highlight and to put one's personal teaching subject in the first room and not see the other subjects taught in school as equally important. In order to find new ways of capturing their own subject's content, the teachers found the framework developed in this action research project, and described in this chapter, as a helpful tool supporting them in exploring and elaborating design aspects with an emphasis on teaching content, not least in planning and evaluating the lessons. When analyzing the lessons afterwards, both teachers realized that they had helped each other with maintaining the other's subject knowledge. Also, when approaching the teaching content from a design sequence and a praxeology perspective, they realized what was actually taking place in the lessons and the actual content the students came into contact with. They could, therefore, use the framework as a guiding tool when carrying out subsequent lessons. If, for example, they realized, when evaluating and analyzing a specific lesson, that the technology for a specific technique was missing, they could keep that in mind before and during the next lesson, while also making well-founded decisions on which modes could be part of the transformation units of the teaching. Hence, the teachers not only developed the lessons consisting of collaborative teaching, but also subsequent lessons where mathematics and styling were taught independently.

Based on how the framework of this chapter was adopted, it is also possible to adopt in relation to other educational knowledge areas (than mathematics and vocational content, as in this chapter), not least when different school subjects are taught together. The ideas of the Learning Design Sequence are not bound to any specific context or content, and nor is praxeology. Our hope is that the version of the Learning Design Sequence in Figure 5.4 along with the analytical model for the analysis of praxis and logos (Table 5.1), may constitute a framework for the research and design of collaborative teaching, with an interest in a variety of knowledge aspects. 


\section{Acknowledgements}

This research was funded by AcadeMedia Inc. Additionally, we are thankful to the teachers and students at Praktiska gymnasiet Liljeholmen who participated in the project, which was the basis for this chapter, especially Divo Racheed.

\section{References}

Bernstein, B. (2000). Pedagogy, symbolic control and identity: Theory, research, critique (Rev. ed.). Rowman \& Littlefield.

Boistrup, L. B., Bellander, E., \& Blaesild, M. (2018). Mathematics in pre-vocational education: A model for interfaces between two different teaching contents. In A. Rogers, B. Street, K. Yasukawa, \& K. Jackson (Eds.), Numeracy as social practice: Global and local perspectives (pp. 76-98). Routledge.

Boistrup, L. B., \& Lindberg, V. (2020). Challenging theory versus practice: Connections between mathematics and vocational education. In Proceedings of CIEAEM71. QRDM, 7, 475-481.

Boistrup, L. B., \& Samuelsson, J. (2019). Power-relations in participatory action research projects in mathematics education. In Proceedings of CIEAEM 70, 15th-19th July 2018, University of Mostaganem, Algeria. Quaderni di Ricerca in Didattica Mathematics, 2(3).

Bosch, M., \& Gascón, J. (2014). Introduction to the Anthropological Theory of the Didactic (ATD). In A. Bikner-Ahsbahs \& S. Prediger (Eds.), Networking of theories in mathematics education (pp. 67-83). Springer.

Castela, C. (2015). When praxeologies move from an institution to another one: The transpositive effects. Mathematics, Science and Technology Education for Empowerment and Equity, 23rd Annual Meeting of the SAARMSTE (Southern African Association for Research in Mathematics, Science and Technology Education), (pp. 6-19).

Chevallard, Y. (2006). Steps towards a new epistemology in mathematics education. In M. Bosch (Ed.), Proceedings of the 4th conference of the European society for research in mathematics education (pp. 21-30). CERME 4.

Engeström, Y. (2001). Expansive learning at work: Toward an activity theoretical reconceptualization. Journal of Education and Work, 14(1), 133-156.

FitzSimons, G. E. (2002). What counts as mathematics? Technologies of power in adult and vocational education. Kluwer Academic Publishers.

FitzSimons, G. E. (2015). Learning mathematics in and out of school: A workplace education perspective. In U. Gellert, J. Giménez Rodríguez, C. Hahn, \& S. Kafoussi (Eds.), Educational paths to mathematics: A C.I.E.A.E.M. sourcebook (pp. 99-115). Springer. https://doi.org/ 10.1007/978-3-319-15410-7-5

Frejd, P., \& Muhrman, K. (2020). Is the mathematics classroom a suitable learning space for making workplace mathematics visible? An analysis of a subject integrated team-teaching approach applied in different learning spaces. Journal of Vocational Education \& Training. https://doi.org/10.1080/13636820.2020.1760337

Kress, G. (2017). Semiotic work: Design, transformation, transduction. In E. Insulander, S. Kjellander, F. Lindstrand, \& A. Åkerfeldt (Eds.), Didaktik i omvandlingens tid: Text, representation, design (pp. 39-51). Liber.

Rosvall, P.-A., Hjelmér, C., \& Lappalainen, S. (2017). Staying in the comfort zones: Low expectations in vocational education and training mathematics teaching in Sweden and 
Finland. European Educational Research Journal, 16(4), 425-439. https://doi.org/10.1177/ 1474904116669154

Selander, S. (2006). Kunskapsformer, topiskt tänkande och tolkningspraktiker [Forms of knowledge, topical thinking and practices of interpretation]. In A. Bronäs \& S. Selander (Eds.), Verklighet verklighet: Teori och praktik i lärarutbildning (pp. 25-40). Norstedts.

Selander, S. (2008). Designs for learning: A theoretical perspective. Designs for Learning, 1(1). Selander, S. (2017). Didaktiken efter Vygotskij-design för lärande [Post-Vygotskian education: Designs for learning]. Liber.

Selander, S. (2018). Can a sign reveal its meaning? On the question of interpretation and epistemic context. In S. Zhao, E. Djonov, A. Björkvall, \& M. Boeriis (Eds.), Advancing multimodal and critical discourse studies (pp. 67-79). Routledge.

Williams, J., \& Wake, G. (2007). Black boxes in workplace mathematics. Educational Studies in Mathematics, 64(3), 317-343. 